\title{
ECDL - A BASIC TOOL FOR SMART CITIES
}

\author{
Ronald Bieber ${ }^{1}$
}

\begin{abstract}
Digital Transformation is changing our society as a whole. New digital skills are required in order to be able to participate in the daily life and work. The OCG has designed a concept "Education 4.0" which enables digital basic skills to everyone. The ECDL - a longstanding worldwide accepted IT certificate - plays an important role within this concept.
\end{abstract}

Keywords: ECDL, digital competences, certificate, digital skills, Education 4.0

\section{Introduction}

\subsection{Digital competence}

Digital competences belong to one of the eight key competences of the European Union which were announced as fundamentals for every individual living in a knowledge based society. The European Commission defines digital competence as a critical and confident usage of information and communication technologies for work, leisure and communication [1]. This is in accordance to OCG initiative outlined in subsection 1.2.

A statistic arising from the Digital Single Market of the European Union [2] shows that 169M people between the age of 16 and 74 within the European Union do not have basic digital skills, i.e.: $44 \%$ of the European Union population. In this statistic Austria is placed in the better third of all EU-28 countries, ending up with still one third of its population having no or low digital skills as it is depicted in Figure 1. This number unfortunately has not been improved over the last decade. By a closer view to the Digital Economy and Society Index (DESI) of the European Union, Austria has especially in the field of human capital - which implies the required digital skills to benefit from the digital society - and integration of technologies in public and private sector a good standing. Austria is located in the group of the medium-performance countries, which are doing well in certain areas but still need progress in others.

However, there is a clear call for action since several studies predict that within 2020 nine out of ten jobs require at least basic digital skills knowledge.

\footnotetext{
${ }^{1}$ OCG Austrian Computer Society, Wollzeile 1, 1010 Vienna Austria, ronald.bieber@ocg.at, www.ocg.at
} 


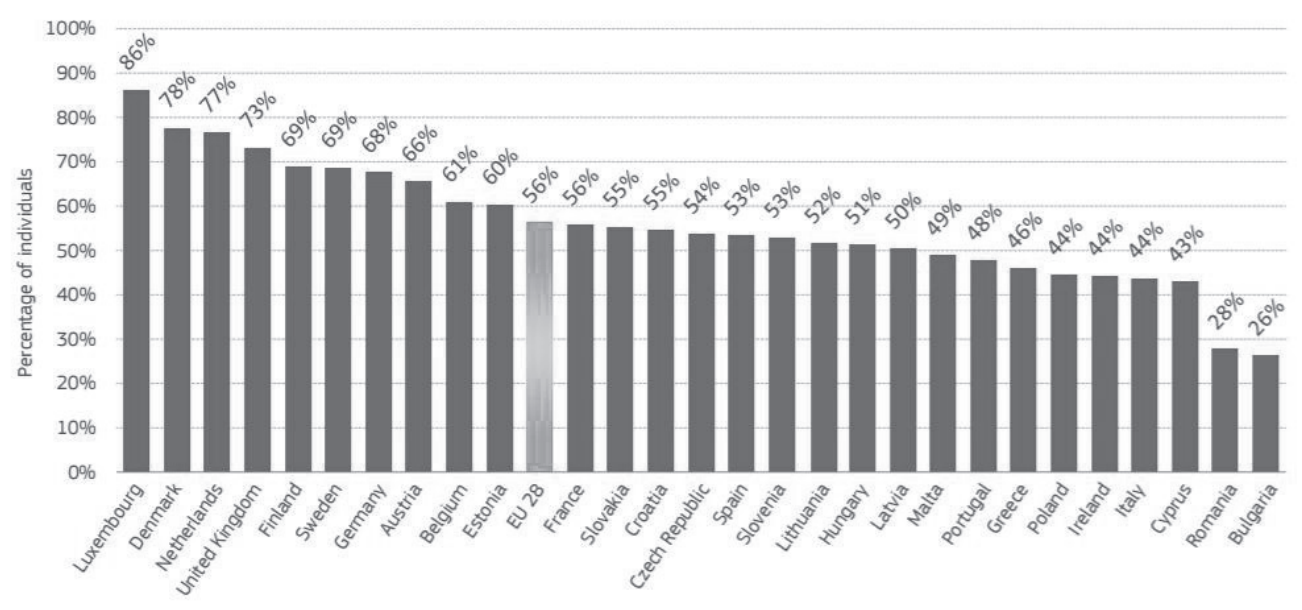

Figure 1: Basic Digital Skills within the EU, 2016, European Commission, Digital Single Market, The Digital Skills Gap in Europe [2]

Digitalization is more and more becoming the driving force today, both in business and in private life [3]. This digital transformation or revolution is after the steam, steel, electricity and petrochemical revolutions, a new change and impulse. The main question is not only what we produce, but also how we produce and how we organize it as a society.

An important driver of the digitalization process is a life long learning attitude among citizens. Hence, earning, updating and reskilling digital skills is one of the main common strategic goals of the government [5]. According Eurostat [6] Austria is on eight place within EU-28 by the percentage of adults doing further education. 14,4\% of Austrian people between the age of 25 and 60 are doing further training (EU-28 average reaches only 10,7\%). However, there is still a lot additional potential. The leaders, countries like Switzerland and the Nordics, reach values of almost one third of its population doing a separate educational training.

The author of the Digital evolution [5] emphasizes that especially in the educational sector a change of mindset is mandatory. On the one hand digital skills shall already be introduced in primary school sector while on the other hand further education has to be promoted and offered on a low level basis. Besides these actions ICT professional skills have to be established too. Here a clear commitment by the government for a better support in all informatic studies at universities has to be provided. Currently one can study Informatics at eight Austrian universities. Just recently the new Austrian government announced to enhance the number of possible informatic students in Austria by 300 students per year in total.

\subsection{Digital competences are a key factor for each economy}

A study of the Institute for economic scientific research among Austrian Companies done in 2017 summarizes that about $90 \%$ of the companies believe that the current digital transformation ("industry 4.0") is changing their business processes within the next five years. Therefore an increased demand of ICT experts and manpower with digital skills is present. One of the key factors is that the individual is willing for doing further education with respect to digital skills [7]. 
The more general benchmark which is regularly performed other most European countries and others is the Programme for International Student Assessment (PISA) study of the OECD [8].

This representative study shows that Austria has a remaining gap within the STEM subjects. Figure 2 depicts the development of the last ten years of Austrian students compared with Germany. In all fields Austria has worse results than Germany but even worse the tendency is decreasing in all fields under investigation. In order to have a strong economy one has to have a strong well educated human capital.
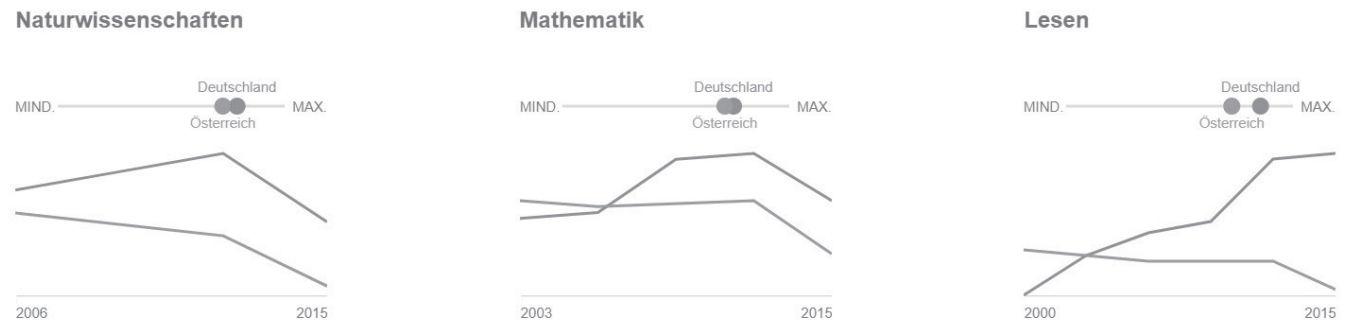

Figure 2: Competences of averaged 15 year old students in STEM (graphic on the left), mathematics (graphic in the middle) and reading (graphic on the right) - results from Germany (blue curve) and Austria (orange curve) [8]

In another special PISA test which is focused on problem solving within a team Austrian students ended up slightly above the average OECD level (score: 509 versus 500). While in the classis PISA tests male students show normally better results than female ones this is the other way round by problem solving tasks. Here the female students had a much higher score than the male (521 versus 498 in Austria).

However, Austria is placed in the middle block of countries and leaves countries like France, UK, Italy or Slovakia behind, the typical leaders are again present, like Singapur (561), Japan (552) or the Nordic countries and also Germany (525).

Due to these facts the Austrian Computer Society started 2016 an initiative in order to enhance digital skills competences within the Austrian population - the so-called Education 4.0 initiative which is outlined in subsection 1.3.

\subsection{Education 4.0 - an initiative of the Austrian Computer Society (OCG)}

The Austrian Computer Society, a non-profit association for the promotion of information technology with due regard to the interaction with people and society, was founded in 1975 and has currently about 1.400 members out of science, economy and public sector. The association acts as an interdisciplinary forum for the latest IT topics, it is an important and respected dialogue partner and has thematic leadership for socio-political IT topics. 
OCG's initiative "Education 4.0" is based on a three pillar concept which are [9]:

- $\quad$ Computer science, informatics

- Digital literacy and

- $\quad$ Digital media literacy

This concept is similar to the one of the Hasler Stiftung in Switzerland, who developed a new curricula for the german speaking Cantons in Switzerland. The so-called "Lehrplan 21" [10] is now in place and will be implemented in the swiss school system. Media and informatics should become a self standing subject while digital literacy should be implemented within other subjects.

Skills in science, technology, engineering and math (STEM) are becoming an increasingly important part of basic literacy in today's knowledge economy. Therefore it is essential to be on the forefront of the debate on how to attract more young people to science and technology and how to implement digital literacy in school system. Figure 3 shows OCGs education 4.0 concept at a glance.

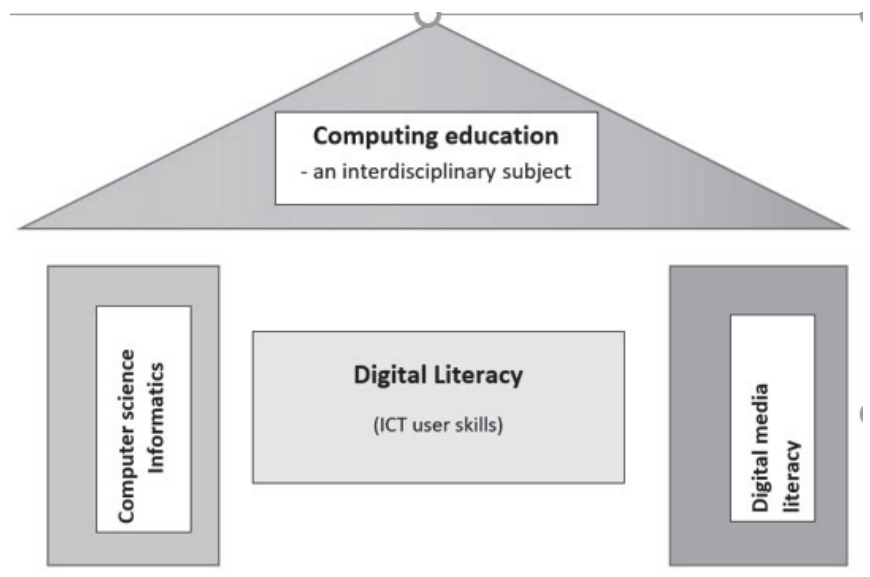

Figure 3: The concept of Education 4.0 - an initiative of the OCG

J. Wing [4] emphasizes that computational thinking is a fundamental skill for everyone. The synonym "computational thinking" was invented around 1980 by Semour Papert, the founder of constructionism. It summarizes basic concepts, tools as well as methods of informatics. It is about looking at a problem in a way that a computer can help us to solve it. This is a two step process: first we think about the steps needed to solve a problem and secondly we use our technical skills to get the computer working on the problem. The focus is towards conceptualizing and not programming. Computational thinking does not necessarily assume experiences on programming but explains concepts and methods of informatics with clarity and depth. Such skills are covered by the first pillar on Education 4.0 "Computer Science, Informatics" and can already be taught in an early stage of education. 
The third pillar "Digital Media literacy" means the critical, secure way of how to find and to get information out of internet. Here, OCG is collaborating with several other non-profit associations which have a good network within the school system.

Last but not least, the second pillar "Digital Literacy" means the ICT user skills in general. These skills are mainly covered by the well established European Computer Driving Licence (ECDL), which itself is a success story over the last 20 years in Austria.

The whole initiative "Education 4.0" of the OCG is supported by several well-known associations, like the Swiss Informatic Society, ICT Austria or Digital City Vienna.

\subsection{ECDL and its international success}

\section{History of ECDL:}

The European Computer Driving Licence (ECDL) was founded by a handful European Computer Socities in order to enhance Computer skills in a time when computers were starting to find their way into the working areas. This unique initiative arised from Europe and slowly but continuously it was and is still spreading over the whole world. Currently ECDL/ICDL (International Computer Driving Licence) is established over more than 140 countries in the world. But still $75 \%$ of tests are done within Europe but numbers are continuously decreasing compared with the rest of the world especially in Asia.

One of the first successful implementations of ECDL happened in the Scandinavian countries where a huge number of companies implemented ECDL in their further education of employees. But as soon as every employee has had the certificate no more interest was given. Neither in the school system nor in the unemployed sector the ECDL was established there.

Another development of ECDL happened in Middle Europe. In Italy, UK and also Austria this certificate was soon recognized by Ministery of education and found its way in each particular school system. In Ireland the government soon saw the importance of such a knowledge and introduced it within their public officers as a mandatory certificate.

In absolute numbers only United Kingdom and Italy has up to now more ECDL participants than Austria. Last year Austria was celebrating 20 years anniversary of ECDL and its 500.000 participant. If one looks to the density (number of certificates versus inhabitants) of ECDL diploma holder in each country Austria is ranked in the top four: first place is Malta (it has mandatory ECDL for all school children), second place is Ireland (it has mandatory ECDL for all public officer) and third is Liechtenstein (also established in school system) and on fourth place already Austria is placed. This is due to the outstanding and long established tradition of ECDL in schools and unemployed sector.

The reason for Austrias outstanding numbers are manifold. One important issue certainly is that OCG is heavily involved in several strategic groups of the ECDL foundation, which on the one hand is responsible for operating the ECDL worldwide and on the other hand takes care on new development of modules. Nowadays the ECDL is made for a lifelong learning process. Each participant can and should update her/his skills regularly and can do new modules depending on the needs. 
ECDL is a unique product which has overcome more than 20 years in the ICT sector. Over this period the ECDL has performed several changes in the product line. However, one topic remained constant, it is - that ECDL stands for digital skills knowledge.

\section{Structure of ECDL in Austria:}

The current ECDL in Austria is clustered in a Base and in a Standard Certificate. The Base consists of four modules namely Computer Essentials, Online Essentials, Word Processing and Spreadsheets. The Standard certificate has seven modules and besides the one of the Base the user can choose three out of five additional modules (presentation, Using Databases, IT Security, Online Collaboration and Image Editing). Besides such standard modules the OCG offers also ECDL Advanced certificates in Word processing, spreadsheets, presentation and Databases, which goes far beyond the common knowledge and shows that the user has professional experiences in using one of these four modules.

This year OCG is planning to install two new ECDL modules: Computing and data protection. The first one is more focused on the school sector while the second one is definitely useful for companies, especially due to the GDPR regulations which will enter into force on $25^{\text {th }}$ of may 2018. Both modules support the approach that ECDL becomes more and more a valid certificate for the workforce and remains a valuable certificate for public and private sector.

The international importance of ECDL is also manifested in the fact that one of the new Board Members of the European Union initiative "Digital Skills and Job Coalition" is the CEO of the ECDL Foundation.

\section{Perception versus reality:}

There is a general public opinion that the so-called digital natives (people below 30 years) are more familiar with digital literacy and are not obliged to learn such skills anymore. Therefore several National Operators of the ECDL carried out a digital literacy study in order to determine the real level of digital skills with respect to the perceptions. The studies were done in Switzerland, Denmark, Finland, Germany, India, Singapore and Austria [11] based on similar methods. First participants were asked to self assess their digital skills and second they underwent some practical questions within the requested fields. The results were consistent among the different countries. There was a clear indication that people cannot adequately assess their digital skills. While in Austria $94 \%$ of all participants thought to have good or very good general digital skills only $39 \%$ ended up with good or very good skills. Singapore - a country always in the top ranking regarding digitalization - shows clearly better results than Austria (55\% versus 39\%). Nevertheless the self assessment is also far away of the real digital knowledge (88,5\% versus $55 \%)$ as it is depicted in Figure 4. In all cases the gap between perception and real knowledge increased for the so-called digital natives compared with the older generation. 

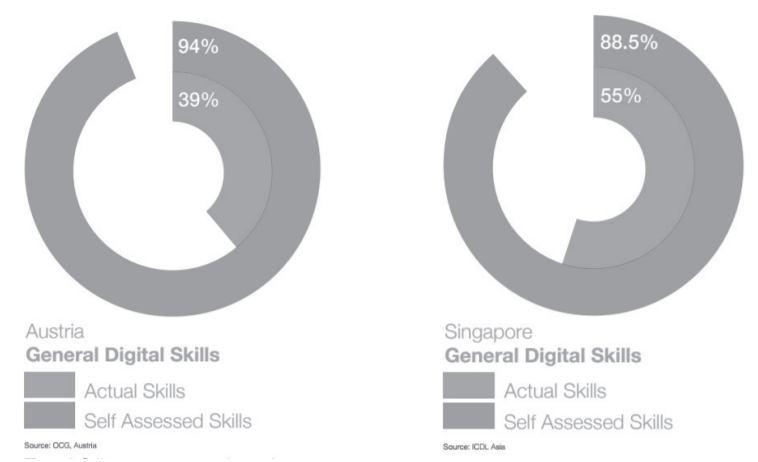

Figure 4: Perception versus reality: General digital skills among Austrian and Singapore population [8].

These results underline the importance of ECDL knowledge also for the younger generation. In Austria the ECDL has also found its way into the public sector. This will be more thoroughly outlined in chapter 2.

\section{ECDL within the Austrian public sector}

The main two economic sectors currently - where ECDL in Austria is in use - are schools and the unemployed market. Besides this the OCG is looking forward that ECDL is more and more accepted within the public (and also private) sector.

One of the first ECDL public test centers of the OCG was the Ministery of Defence in the beginning of the year 2000. Up to know more than 10.000 officers from the ministery have started the ECDL. Almost half of them have finalized all seven ECDL standard modules.

An even more admirable number are the almost 800 graduated participants who have passed an ECDL Advanced certificate - 113 out of them have even finished all four ECDL Advanced modules and can call themselves an ECDL Expert.

However, on the one hand due to a permanent budget reduction within the Austrian Ministery and on the other hand due to the fallacy of digital natives ICT skills knowledge the ECDL program within the Ministery of Defense has been reduced drastically. So the ECDL unfortunately never got really launched for recruits.

Another Austrian Ministery which counts on the international ECDL certificate is the Ministery of Justice. Several prisons spread over Austria provide ECDL for its prisoners. More than 1000 prisoners have till now successfully passed the ECDL standard - one third of these participants has even obtained an ECDL Advanced certificate. OCG is proud that Austrias biggest youth prison (Josefstadt in Vienna) has been a long standing partner and offers the ECDL for its young prisoners. This is only possible since the public servants who are responsible for the internal process are looking for pragmatic solutions and the OCG has arranged a special agreement with the ECDL Foundation in order to allow tests within prisons. The OCG is still searching for getting the ECDL established within the officers of the Ministery of Justice, too. 
Since a couple of years the Administration Academy of the Viennese public officers is cooperating with the OCG in order to enhance its digital skills among their employees. More than 50.000 public officers are working for the Vienna city. A study from the Netherlands [12] came to the conclusion that good digital literacy skills like word processing or spredsheets can finally sum up in a time saving of more than $2 \%$ per each working day. If you assume that a common medium enterprize has about 70 office workers sitting most of their time behind the computer you end up with a yearly saving rate of more than $100.000 €$. This high amount (more than one Full Time Equivalent) can be saved only due to well educated people who know how to work efficiently on the computer. The Administration Academy of Vienna has just started the program with OCG. In the first year it evaluated the typing skills among their employees. The last year they already started small office tests in order to judge where the gaps are and which actions should be taken into account in the next upcoming phase.

During the last year the Austrian police academy signed a contract where they committed to the ECDL certification for every student of the police academy in Austria. Currently more than 2.000 students are starting every year this school. According to the Ministery of Interior the number of police students should increase continuously the upcoming years.

The head of the police acadamey knows that basic digital skills are preconditions for a digitalized work. The current ECDL is a mixture of digital literacy and basic know how of media competences. Especially basic knowledge as IT Security and data protection are requirements for police further education. Additionally the Ministery committed to the ECDL for the next five years at minimum.

These few examples show on the one hand the importance of digital literacy within the public sector and on the other hand also the possibilities which the ECDL certificate can give for people in the workforce.

\section{Midterm goals of the OCG}

Smart cities can only exist with smart people who knows how to deal with all the digitalized technologies which should support their life. However, it has to be stated that the public sector has other criteria regarding the economical growth as the private sector. Nevertheless one of the major goals of the OCG is to minimize the digital analphabet among Austrians citizens. As stated in the first chapter currently almost one third of all Austrians have no or low digital skills. This number is too high for being able to compete with the best of the world.

In this sense OCG claims a continuos digital education from primary school up to university level. Starting with gaming in which the children get the first impression of computational thinking. In the lower secondary school digital literacy shall be focussed on, which is mainly covered by the ECDL. Finally the students should come in touch with computing, coding and especially media competences. OCG is still fighting for a mandatory digital acceptance test (or even better an ECDL certificate) for university entry. This was established in Italy for some particular universities. Universities are still searching for new students since companies baits graduated secondary higher school leaver in the IT sector with a high starting salary.

OCG believes that with such an educational concept described in section 1.2 Austria certainly can reduce the leak of ICT experts. 


\section{Summary and Outlook}

Digitalization is the driving force today, both in private life and in business [3]. It is more than just an ICT phenomenon but more a technological trend that has impact on society as a whole.

Therefore OCG has developed together with its experts from science and economy an educational concept for bringing digital skills to everyone (Edcuation 4.0) - a major part for success is the international ECDL certificate which OCG promotes and operates since 20 years. ECDL is a success story in Austria and is becoming a more and more important role within the public sector.

The biggest challenges in order to spread digital knolwedge among citizens are on the one side the fallacy that digital natives have already dgital skills for workforce and on the other side the mistake of numerous stakeholders to believe that basic digital skills are not needed at all anymore or that these skills are anyhow already known.

\section{Literature}

[1] Recommendations of the European Union (Rec/2006/962/EC) on key competences for life long learning.

[2] Digital Single Market EU https://ec.europa.eu/digital-single-market/en/news/digital-skillsgap-europe

[3] VOGELSANG, M. (2010), Comparison of the Models. In Digitalisation in Open Economies (pp. 141-146), Physica-Verlag HD

[4] WING, J. M. (2006), „Computational Thinking“, Communications of the ACM 49 (3)

[5] Die Digitale Evolution, Policy Brief Nr.34 (05/2017), Kompetenzzentrum „Forschungsschwerpunkt Internationale Wirtschaft", BMWFW

[6] Eurostat, Participation in education and training (based on EU-LFS)

[7] Studie von dem Industriewissenschaftlichen Institut (IWI) bezüglich Industrie 4.0 (https://www.propak.at/ ) or (https://news.wko.at/news/oesterreich/PROPAK-4.0---EineBranche-im-digitalen-Wandel-PWK855-US-1.html)

[8] OECD, Programme for International Student Assessment http://www.oecd.org/berlin/ themen/pisa-studie/

[9] Bildung 4.0, Eine Initiative der Österreichischen Computer Gesellschaft (2016)

[10] Deutschschweizer Erziehungsdirektoren-Konferenz (D-EDK) https://www.lehrplan.ch/

[11] ECDL Foundation, Perception \& Reality, Position paper of the ECDL Foundation, http://ecdl.org/ecdl-news?i=3027 (last view: 05.02.2018)

[12] CTRL-ALT-DELETE, Lost productivity due to IT problems and inadequate computer skills in the workplace, Universiteit Twente, Netherlands (2012) 